\title{
Intervensi Sosial dalam Manajemen Pendidikan Inklusif Dinas Pendidikan Kebudayaan Kepemudaan dan Olahraga Kabupaten Semarang
}

\author{
Thea Rahmanindita Esperanza ${ }^{1}$, Titik Djumiarti ${ }^{2}$ \\ ${ }^{1}$ Administrasi Publik, Fakultas Ilmu Sosial dan Ilmu Politik, Universitas Diponegoro \\ ${ }^{2}$ Administrasi Publik, Fakultas Ilmu Sosial dan Ilmu Politik, Universitas Diponegoro
}

\begin{abstract}
The implementation of inclusive education in Semarang is still experiencing various obstacles. The aim of this research is to analyze the social intervention conducted by the Education Office, Culture, Youth and Sports District of Semarang in the implementation of an inclusive education of elementary school level, by looking at the intervention process carried out and the constraints contained therein. This research uses qualitative methods of descriptive. The results showed that the management of inclusive education in Semarang Regency isn't optimal, because there is still an intervention process that is not seen in the implementation of inclusive education by the Semarang District Education Office. The advice that researchers can provide is the addition of quotas for the ABK to school and the addition of budgets intended for the recruitment process of special escort teachers, special escort teachers 'benefit, procurement of infrastructure and maintenance.
\end{abstract}

Keywords: Social intervention, management, inclusive education

\section{Pendahuluan}

Perkembangan sekolah inklusif di Jawa Tengah dalam jurnal yang berjudul Evaluasi Pendidikan Inklusif Bagi Anak Berkebutuhan Khusus (Abk) Di Provinsi Jawa Tengah menyebutkan bahwa Dinas Pendidikan Provinsi Jawa Tengah pada tahun 2010 mengadakan 160 (seratus enam puluh) sekolah inklusif rintisan yang disertai dengan pemberian dana operasional bantuan sosial bagi sekolah-sekolah rintisan tersebut. Pendidikan Inklusif dalam (Kurth et al., 2018, p. 29) dijelaskan sebagai sebuah proses untuk membantu mengatasi hambatan dalam kehadiran, partisipasi dan prestasi di kelas pendidikan umum, pendidikan yang inklusif diharapkan dapat meningkatkan dan memperkuat sistem pendidikan untuk semua pelajar. Hingga pada tahun 2015 Seluruh sekolah inklusi di Provinsi Jawa Tengah mencapai 519 sekolah, dalam proses penerimaan siswa baru ABK tidak ada yang memberikan batasan/kuota bagi ABK. Akan tetapi, pelaksanaan proses penerimaan siswa baru $\mathrm{ABK}$ di Provinsi Jawa Tengah khususnya pada saat pelaksanaan identifikasi 
dan penilaian dijalankan dengan cara yang berbeda-beda dengan kata lain belum ada keseragaman dalam proses pelaksanaannya (Haryono, Ahmad Syaifudin, 2015). Pendidikan inklusif diselenggarakan oleh sekolah inklusif dimana sekolah inklusif merupakan sekolah negeri dan memiliki akreditasi A. Sekolah ini hampir sama dengan Sekolah Luar Biasa hanya saja proses penerimaannya berbeda dengan SLB. Pada perkembangannya, sebanyak 519 sekolah yang menyatakan sebagai sekolah inklusi, namun, guruguru masih membutuhkan tambahan pembekalan/pelatihan pendidikan inklusif terutama dengan urusan administrasi.

Kabupaten Semarang, melalui data dari Dinas Pendidikan Kebudayaan Kepemudaan dan Olahraga menunjukkan bahwa jumlah sekolah dasar (SD) di Kabupaten Semarang sebanyak 455 sekolah dasar negeri dan 45 sekolah dasar swasta, total jumlah sekolah dasar negeri maupun swasta yang terdapat di Kabupaten Semarang sejumlah 498. Dari 498 sekolah dasar di Kabupaten Semarang, sekolah yang tepilih untuk menyelenggarakan pendidikan inklusif dan telah diresmikan yaitu 14 Sekolah Dasar Negeri.

Sekolah Inklusi yang terpilih ini ditetapkan melalui SK Kepala Dinas Pendidikan, Kebudayaan, Kepemudaan dan Olahraga Kabupaten Semarang Nomor 421.2 / 106 / 2019 Tentang Penetapan SD Pelaksana Program Inklusi Kabupaten Semarang yang mulai berlaku pada tanggal ditetapkan 17 Januari 2019. Regulasi ini seharusnya semakin mendorong pemerintah Kabupaten Semarang untuk serius dalam memberikan pendidikan yang sama bagi anak berkebutuhan khusus. Dinas Pendidikan, Kebudayaan, Kepemudaan dan Olahraga pada tahun 2020 ini sedang melakukan pengembangan secara serius untuk sekolah inklusi ini, diharapkan dapat memberikan dampak positif bagi sekolah dan anak berkebutuhan khusus. Akan tetapi, berdasarkan hasil pra-penelitian peneliti terkait permasalahan yang dihadapi dalam penyelenggaraan inklusif, permasalahan yang paling menonjol adalah mengenai : Pertama, Ketersediaan guru pembimbing khusus yang masih kurang dibeberapa sekolah dasar. Kehadiran guru pembimbing khusus setidaknya terdapat 1 di setiap kelas dimana didalamnya terdapat ABK. Namun, kondisi dilapangan menunjukan bahwa dalam 1 sekolah hanya terdapat 1 guru pembimbing bahkan ada beberapa sekolah yang tidak memiliki guru pembimbing khusus. Kedua, Sarana prasarana yang belum mengakomodasi hadirnya anak berkebutuhan khusus di sekolah regular. Pemerintah Kabupaten Semarang berencana untuk menyediakan ruangan khusus bagi ABK agar tidak terganggu dengan anak-anak lainnya dalam proses belajar mengajar, namun hingga kini rencana tersebut belum terealisasaikan. Selain itu terdapat kesenjangan fasilitas di beberapa sekolah hal ini dikarenakan penyediaan fasilitas sarana prasarana saat ini disesuaikan kemampuan sekolah, ada yang memiliki sarana prasarana untuk terapi ABK di sekolah, ada yang tidak memiliki sarana tersebut bahkan ketersediaan buku-buku braile juga terbatas. 
Permasalahan - permasalahan yang ditemukan pada kegiatan prapenelitian menunjukan jika pengelolaan atau manajemen dari penyelenggaraan pendidikan inklusif di Kabupaten Semarang belum berjalan dengan maksimal. Manajemen, menurut Siagian (Siagan, 2012, p. 5) dapat didefinisikan dari dua sudut pandang, yaitu sebagai proses penyelenggaraan berbagai kegiatan dalam rangka penerapan tujuan dan sebagai kemampuan atau keterampilan orang yang menduduki jabatan manajerial untuk memperoleh sesuatu hasil dalam rangka pencapaian tujuan melalui kegiatan-kegiatan orang lain. Manajemen, didalamnya terdapat beberapa fungsi yang seringkali digunakan untuk menjadi patokan dalam menyelenggarakan sebuah kegiatan pengelolaan agar kegiatan pengelolaan tersebut berjalan dengan baik. George R. Terry dalam buku Ilmu Administrasi Publik (Inu Kencana Syfiie, 2010) menyebutkan bahwa terdapat 4 fungsi dasar dalam manajemen yaitu:

1. perencanaan (planning),

2. pengorganisasian (organizing),

3. pengarahan (actuating),

4. pengawasan/pengendalian (controlling)

Fungsi-fungsi inilah yang seringkali diterapkan dalam sebuah organisasi untuk melaksanakan kegiatan demi mencapai tujuan yang telah ditetapkan.

Dinas Pendidikan Kabupaten dalam menghadapi permasalahanpermasalahan tersebut berusaha untuk melakukan intervensi sosial didalamnya melalui beberapa hal, salah satunya adalah meminimalisir keterbatasan-keterbatasan yang mungkin dihadapi oleh Anak
Berkebutuhan Khusus dalam bersekolah di Sekolah Dasar Inklusif termasuk didalamnya menyiapkan fasilitas bagi para ABK ini.

Intervensi sosial (dalam Hardjomarsono, n.d., p. 4) adalah tindakan yang bertujuan untuk membantu orang perorangan atau kelompok atau keluarga atau komunitas dalam konteks kehidupan sosial. Kemudian, Pincus dan Minahan dalam (Raharjo,2017) , intervensi sosial meliputi tahapan sebagai berikut : (1) Penggalian Masalah; (2) Pengumpulan Data; (3) Melakukan Kontak Awal; (4) Negosiasi Kontrak; (5) Membentuk Sistem Aksi; (6) Menjaga dan Mengkoordinasikan Sistem Aksi; (7) Memberikan Pengaruh; dan (8) Terminasi

Dari uraian sebelumnya, penelitian ini berusaha untuk menganalisis lebih lanjut bagaimana proses intervensi sosial yang dilaksanakan oleh Dinas Pendidikan Kabupaten Semarang dalam penyelenggaraan pendidikan inklusif pada sekolah dasar inklusif.

\section{Metode Penelitian}

Penelitian ini menggunakan pendekatan deskriptif kualitatif. Menurut Nana (2007:72) Pendekatan kualitatif merupakan salah satu pendekatan yang dilakukan untuk mendeskripsikan atau menggambarkan fenomenafenomena yang ada, baik fenomena yang bersifat alami atau rekayasa manusia. Desain penelitian yang digunakan dalam penelitian ini adalah penelitian deskriptif yaitu untuk mendeskripsikan gejala sosial tertentu, dalam hal ini gejala sosial dilihat dari permasalahan pendidikan inklusif di Kabupaten Semarang. 
Penelitian ini berlokasi di Dinas Pendidikan, Kebudayaan, Kepemudaan dan Olahraga Kabupaten Semarang karena dinas pendidikan yang dalam hal ini menangani penyelenggaraan Pendidikan Iklusif. Adapun dalam penelitian ini, informan ditentukan dengan teknik snowball sampling, yaitu proses penentuan informan berdasarkan informan sebelumnya tanpa menentukan jumlahnya secara pasti dengan menggali informasi terkait topik penelitian yang diperlukan. Dalam penelitian ini menggunakan dua sumber data yaitu data sekunder dan data primer namun lebih mengutamakan analisis data sekunder, untuk mengumpulkan data tersebut penulis menggunakan teknik pengumpulan data yaitu: Studi Pustaka, Observasi, dan Wawancara/Interview. Data-data yang telah diperoleh dari hasil pengumpulan data selanjutnya disusun untuk kemudian disajikan dan dianalisis menggunakan metode kualitatif dengan teknik analisis data milik Spradley dalam Sugiyono (2016, pp. 345-362) dimana Penelitian ini dimulai dari memilih situasi sosial; yang dilanjutkan dengan melaksanakan observasi partisipan; selanjutnya mencatat hasil observasi dan wawancara; dilanjutkan dengan melakukan observasi deskriptif, kemudian melakukan analisis domain; yang dilanjutkan dengan melakukan observasi terfokus; kemudian melaksanakan analisis taksonomi dan melakukan observasi terseleksi dan selanjutnya melakukan analisis komponensial. Keabsahan data di lakukan dengan teknik triangulasi sumber. Penelitian terbagi menjadi 3 tahap mulai dari tahap pra- lapangan, tahap pekerjaan lapangan, dan tahap analisis data.

\section{Hasil dan Pembahasan}

Tahapan pelaksanaan intervensi sosial menurut Pincus dan Minahan (1973:101-117) dalam Social Work Journal (2014:187) terdiri dari: penggalian masalah, pengumpulan data, melakukan kontak awal, negosiasi kontrak, membentuk sistem aksi, menjaga dan mengkoordinasikan sistem aksi, memberikan pengaruh, dan terminasi. Tahapan tersebut selanjutnya menjadi perhatian peneliti untuk melihat bagaimana proses intervensi sosial yang dilaksanakan dalam manajemen penyelenggaraan pendidikan inklusif di Dinas Pendidikan Kebudayaan Kepemudaan dan Olahraga Kabupaten Semarang.

Hasil penelitian menunjukan bahwa proses intervensi sosial dalam penyelenggaraan pendidikan Inklusif Dinas Pendidikan Kebudayaan Kepemudaan dan Olahraga Kabupaten Semarang adalah sebagai berikut:

1. Proses Penggalian Masalah pada tahap Perencanaan

Dalam tahap ini, masalah utama yang ditemui adalah perilaku Anak berkebutuhan khusus yang berbeda-beda, kemampuan sekolah dalam menyelenggarakan pendidikan inklusi bagi ABK yang terbatas, keterlibatan dari pihak professional yang ahli dalam melakukan assessment yang terbatas. Kondisi masyarakat sekitar Sekolah Dasar Inklusif juga masih awam akan pendidikan ABK. Dengan adanya Program pendidikan 
inkluasif tingkat Sekolah Dasar diharapkan mampu menyediakan layanan pendidikan bagi ABK dan memberi kesempatan belajar pada ABK. Akan tetapi pada proses tahap penggalian masalah, penentuan pihak yang jadi sasaran tidak dijelaskan alurnya dan langsung ditentukan bahwa sasarannya adalah ABK, kemudian strategi yang digunakan juga belum jelas.

2. Proses Pengumpulan Data pada tahap perencanaan

Data yang diperoleh oleh Dinas Pendidikan Kebudayaan dan Pemuda Olahraga Kabupaten Semarang berasal dari laporan tertulis dan dapat diuji kevaliditasannya. Dalam tahap ini dinilai sudah sesuai, akan tetapi masih kurang, karena data dari laporan tertulis saja belum cukup untuk menunjukan realita dilapangan. mempengaruhi proses perencanaan ketika data dalam laporan tidak benar-benar diupdate atau di sesuaikan dengan kondisi terkini maka tahap perencanaan akan kacau. Contohnya, ketika data pada laporan diidentifikasikan bahwa jumlah ABK menurun setiap tahunnya kemudian untuk melakukan efisiensi maka anggaran untuk $\mathrm{ABK}$ dipotong, padahal fakta yang ada jumlah ABK justru mengalami peningkatan hal ini berimbas pada penyediaan fasilitas bagi ABK itu sendiri. Meskipun begitu, data yang diperoleh bisa diuji kevaliditasannya.
3. Proses Kontak Awal pada tahap perencanaan

Komunikasi yang dilakukan Dinas Pendidikan Kebudayaan dan Pemuda Olahraga Kabupaten Semarang dengan masyarakat disekitar Sekolah Dasar Inklusif tidak Nampak dalam proses intervensi sosial yang dilakukan hal ini berdasarkan hasil analisis penelitian dimana komunikasi hanya dilakukan oleh Dinas dan KKKS Layanan Inklusi Kabupaten Semarang melalui rapat koordinasi, tidak ditemukan proses komunikasi dengan masyarakat, hal ini sekaligus menunjukan kurang baiknya tahap pengorganisasian dilihat dari proses intervensi yang tidak sempurna dan akan membuat pelaku intervensi kesulitan untuk menyampaiakan apa yang seharusnya dilakukan oleh para pihak yang terlibat.

4. Proses Negosiasi Kontrak pada tahap pengorganisasian

Kesepakatan diantara pihak Dinas Pendidikan Kebudayaan dan Pemuda Olahraga Kabupaten Semarang merupakan tidak tampak dari hasil analisis penelitian. Masyarakat bahkan pihak sekolah tidak diberi kesempatan untuk berpartisipasi dalam penentuan Sekolah Dasar Inklusi, sehingga masyarakat dan sekolah hanya sebatas menjalankan yang sudah ditentukan oleh Dinas melalui SK Nomor 421.2/106/2019 tentang penetapan SD Pelaksana Program Inklusi Kab. 
Smg tahun 2019 yang berjumlah 14 SD Negeri . Fokus pada tahap intervensi sosial ini adalah Dinas cenderung memutuskan penunjukan dan pelaksanaan pendidikan inklusif bagi Sekolah Dasar tanpa melibatkan masyarakat kemudian, Dinas juga hanya berfokus untuk mengorganisir perwakilan yang tergabung dalam KKK Layanan Inklusif Kabupaten Semarang dan belum melakukan pengorganisasian pada masyarakat. Hal ini akan menimbulkan permasalahan dikemudian hari. Contohnya adalah ketika KKKS Laynan inklusif Kabupaten Semarang mengalami permasalahan maka proses pelaksanaan akan terganggu akibat Dinas yang belum pernah mengorganisasikan masyarakat sehingga ini akan mempersulit pihak Dinas Pendidikan Kebudayaan Dan Pemuda Olahraga Kabupaten Semarang.

5. Proses Sistem Aksi pada tahap pengorganisasian

Sistem atau cara yang digunakan oleh Dinas Pendidikan Kebudayaan Dan Pemuda Olahraga Kabupaten Semarang dalam melaksankan Pendidikan Inklusif di tingkat Sekolah Dasar adalah dengan cara menerapkan system belajar mengajar dengan 1 guru pendamping khusus dalam 1 kelas pada tahap ini Dinas juga mengadakan system pelatihan dan pembinaan bagi pihak Sekolah. Proses penetapan program tidak melibatkan masyarakat dan pihak sekolah sehingga tidak terlihat kontribusi dari masyarakat.

6. Proses Menjaga dan Mengkoordinasikan Sistem Aksi pada tahap pengorganisasian dan tahap pengawasan

Pihak yang terlibat dalam pelaksanaan intervensi sosial adalah Dinas Pendidikan Kebudayaan dan Pemuda Olahraga Kabupaten Semarang, Kelompok Kerja Kepala Sekolah Layanan Inklusi (KKKS) Kabupaten Semarang, dan Guru pembimbing khusus. Untuk menjaga koordinasi dilakukan dengan cara rapat koordinasi yang dilakukan oleh Dinas Pendidikan Kebudayaan dan Pemuda Olahraga Kabupaten Semarang dengan pihak-pihak yang terlibat. Dalam tahap ini dinilai sudah sesuai, karena dalam pelaksanaan intervensi sosial, Dinas Pendidikan Kebudayaan dan Pemuda Olahraga Kabupaten Semarang telah melibatkan pihak-pihak lain meskipun pelibatan tersebut dilaksanakan pada proses pelaksanaan intervensi sosial tidak pada proses perencanaannya. Selain itu, dengan adanya rapat koordinasi, maka komunikasi diantara pihak-pihak tersebut juga akan menjadi lebih mudah.

7. Proses Memberikan Pengaruh pada tahap penggerakan Guna mempengaruhi masyarakat agar berpartisipasi pada program dengan baik dan menyadarkan mereka tentang pentingnya pendidikan bagi 


\begin{abstract}
ABK, maka Dinas Pendidikan Kebudayaan dan Pemuda Olahraga Kabupaten Semarang memotivasi mereka dengan cara pengadaan pameran, gebyar seni. Dalam tahap ini dinilai sudah sesuai, karena dengan adanya motivasi yang diberikan, maka semangat masyarakat Sekolah Dasar Inklusif dalam bekerja juga meningkat. Meskipun, sebagian masyarakat masih malu menyekolahkan anaknya yang berkebutuhan khusus
\end{abstract}

8. Proses Terminasi dalam tahap pengawasan

Tahap terminasi yang dilaksanakan oleh Dinas Pendidikan, Kebudayaan, Kepemudaan dan Olahraga Kabupaten Semarang dapat dilihat dari sudah tidak adanya diskriminasi pada $\mathrm{ABK}$ dalam proses pembelajaran. Namun, pada tahap ini belum terlalu jelas pencapaian dan dampak secara keseluruhan.

\section{Kesimpulan}

Kesimpulan yang didapatkan dari hasil penelitian menunjukan bahwa, penyelenggaraan pendidikan inklusif yang dilaksanakan oleh Dinas Pendidikan, Kebudayaan, Kepemudaan, dan Olahraga Kabupaten Semarang masih belum maksimal. Hal ini dilihat dari manajemen atau pengelolaannya yang masih kurang, dikarenakan masih terdapat beberapa proses intervensi yang tidak nampak dalam pengelolaan tersebut dan kebanyakan berkaitan dengan tahap atau fungsi perencanaan dan pengawasan. Adapaun proses intervensi yang masih belum terlihat atau belum maksimal tersebut adalah:

1. Tahap penggalian masalah, dimana penentuan pihak yang jadi sasaran tidak dijelaskan secara detail.

2. Tahap pengumpulan data yang hanya berdasarkan data dari laporan tertulis saja sehingga belum cukup untuk menunjukan realita dilapangan

3. Tidak terlihatnya proses negosiasi kontrak dengan masyarakat

4. Proses terminasi yang kurang jelas

Adapun kendala yang dihadapi pada proses intervensi tersebut sebagian besar terkendala permasalahan fasilitas dan rendahnya kesadaran masyarakat terhadap pentingnya pendidikan inklusif bagi para ABK.

\section{Penghargaan}

Penelitian ini didedikasikan bagi Universitas Diponegoro selaku tempat penulis bernaung sekaligus persembahan penulis pada proses akhir pembelajaran. Selain itu, penelitian ini didedikasikan bagi Anak-Anak Berkebutuhan Khusus, agar melalui penelitian ini, mereka yang membaca dapat menyadari betapa pentingnya pendidikan inklusif bagi para Anak Berkebutuhan Khusus. Serta menjadi masukan bagi stakeholder terkait untuk memperbaiki penyelenggaraan pendidikan inklusif itu sendiri.

\section{Referensi}

Apri Nuryanto. (2015). MANAJEMEN PERUBAHAN

DALAM 


\section{PENINGKATAN}

MUTU

SEKOLAH (A. Nuryanto, Ed.).

Allen Pincus \& Anne Minahan : "Social Work Practice : Model and Method", FE Peacock Publishers, Inc, Illinois, 1973

BUDIYANTO. (2017). PENGANTAR PENDIDIKAN

INKLUSIF

BERBASIS BUDAYA LOKAL (1st ed.; BUDIYANTO, Ed.). Jakarta: PRENADAMEDIA GROUP.

Dedy Kustawan, Y. M. (2016). Mengenal pendidikan khusus dan pendidikan layanan khusus serta implementasinya (2nd ed.; Y. M. Dedy Kustawan, Ed.). Jakarta: Luxima Metro Meida.

Devecchi, C., \& Nevin, A. (2010). Leadership for inclusive schools and inclusive school leadership. In Advances in Educational Administration (Vol. 11). https://doi.org/10.1108/S1479 -3660(2010)0000011014

Dr. T. Hani Handoko, M. B. . (2015). Manajemen (2nd ed.; M. B. . Dr. T. Hani Handoko, Ed.). Yogyakarta: BPFE Yogyakarta.

Dra. Sari Rudiyati, M. P. (2011). Potret Sekolah Inklusif di Indonesia. Memilih Sekolah Yang Tepat Bagi Anak Berkebutuhan Khusus, 1-25. https://doi.org/10.1027//1016 $-9040.6 .2 .123$

Dunn, W. N. (2003). Pengantar Analisis Kebijakan Publik. Yogyakarta: UGM Press.

Eta Yuni Lestari, S. S. dan N. I. (2017). Pemenuhan Hak Bagi Penyandang Disabilitas Di Kabupaten Semarang Melalui Implementasi Convention on the Rights of Persons With Disabillities (Cprd) Dalam Bidang Pendidikan. Integralistik, 1, 1-9.
Hardjomarsono, B. (n.d.). Pengertian, Ruang Lingkup Dan Studi Intervensi Sosial. 1-65.

Haryono, Ahmad Syaifudin, S. W. (2015). Evaluasi Pendidikan Inklusif Bagi Anak Berkebutuhan Khusus (Abk) Di Provinsi Jawa Tengah. Jurnal Penelitian PendidikanA \& A (Semarang), 32(2), 119-126. https://doi.org/10.15294/jpp.v 32i 2.5057

Hasibuan, M. S. P. (2011). Manajemen Sumber Daya Manusia. Edisi Revisi Jakarta: Bumi Aksara.

Herawati, N. I. (2016). Pendidikan Inklusif. EduHumaniora | Jurnal Pendidikan Dasar Kampus Cibiru.

https://doi.org/10.17509/eh.v2 i1.2755

Inu Kencana Syfiie. (2010). Ilmu Administrasi Publik (Inu Kencan; I. K. SYAFIIE, Ed.). Jakarta: PT Rineka Cipta.

Isbandi Rukminto Adi. (2008). Intervensi Komunitas Pengembangan Masyarakat Sebagai Upaya Pemberdayaan Masyarakat (1st ed.; Isbandi Rukminto Adi, Ed.). Jakarta: PT Raja Grafindo Persada.

Jum Anggraini. (2012). Hukum Administrasi Negara (1st ed.; Jum Anggraini, Ed.). Yogyakarta: Graha Ilmu.

Keban, Yeremia T. (2008). Enam Dimensi Strategis Administrasi Publik Konsep, Teori, dan Isu. Yogyakarta: PENERBIT GAVA MEDIA.

Keban, Yeremias T. (2004). Enam Dimensi Strategis Administrasi Publik: Konsep. Teori Dan Isu, Yogyakarta: Gava Media. https://doi.org/10.1016/j.ijanti micag.2016.05.001 
Kefallinou, A., \& Donnelly, V. (2016). Inclusive assessment: Issues and challenges for policy and practice. International Perspectives on Inclusive Education, 8, 209-227. https://doi.org/10.1108/S1479 $-363620160000008013$

Kurth, J. A., Miller, A. L., Toews, S. G., Thompson, J. R., Cortés, M., Dahal, M. H., ... Wangare, F. (2018). Inclusive education: Perspectives on implementation and practice from international experts. Intellectual and Developmental Disabilities, 56(6), $\quad$ 471-485. https://doi.org/10.1352/19349556-56.6.471

Kustawan, D., \& Hermawan, B. (2013). Model Implementasi Pendidikan Inklusif Ramah Anak (D. Kustawan \& B. Hermawan, Eds.). luxima.

Loreman, T., Forlin, C., Chambers, D., Sharma, U., \& Deppeler, J. (2014). Conceptualising and measuring inclusive education. International Perspectives on Inclusive Education, 3, 3-17. https://doi.org/10.1108/S1479 $-363620140000003015$

Mohamad Mustari. (2014). Manajemen Pendidikan (1st ed.; Rajawall Pers, Ed.). Jakarta: PT RajaGrafindo Persada.

Nuryanto, A. (2015). MANAJEMEN PERUBAHAN DALAM PENINGKATAN MUTU SEKOLAH. Retrieved from http://staff.uny.ac.id/sites/defa ult/files/pengabdian/aprinuryantospdstmt/manajemenperubahan-2015.pdf

Pasolong, H. (2007). Teori Administrasi Publik. Bandung: Alfabeta.
Rodriguez, C. C., \& Garro-Gil, N. (2015). Inclusion and Integration on Special Education. Procedia - Social and Behavioral Sciences, 191, 13231327. https://doi.org/10.1016/j.sbspr o.2015.04.488

Siagan, S. P. (2012). Manajemen Stratejik (9th ed.; Sondang P Siagian, Ed.). Jakarta: Bumi Aksara.

Siahaan, A., \& Zen, W. L. (2012). Manajemen Perubahan (Telaah Konseptual, Filosofis dan Praktis terhadap Kebutuhan Melakukan Perubahan dalam Organisasi) (1st ed.; T. Rafida, Ed.). Bandung: Citapustaka Media Perintis.

Sidiq, F. H. (2019). Komunitas Inisiasi Perda Disabilitas di Kabupaten Semarang. Retrieved April 1, 2020, from Pos Jateng website: https://www.posjateng.id/wart a/komunitas-inisiasi-perdadisabilitas-di-kabupatensemarang-b1Xo29cvR

Sugiyono. (2016). Metode Penelitian Kuantitatif,Kualitatif, dan R\&D. Bandung: Alfabeta

Suwitri, S. (2008). Konsep Dasar Kebijakan Publik. Analisis Kebijakan Publik.

Syafri, W. (2012). Studi tentang Administrasi Publik (1st ed.; W. Syafri, Ed.). Jakarta: Erlangga.

Tarmansyah. (2007). Inklusi Pendidikan Untuk Semua. https://doi.org/IOS4684.JATIM 000000000005235

UNESCO. (2005). Guidelines for inclusion: Ensuring access to Education for All. United Nations Educational, Scientific and Cultural Organization. 
https://doi.org/10.1073/pnas.0 703993104

W. F. Willoughby. (1927). Principles of Public Administration. National Municipal Review, 17(4), 231-232.

Wardani, K. (n.d.). Hakikat Pendidikan Khusus. 1-51.

Widyawati, R. (2017). Evaluasi Pelaksanaan Program Inklusi Sekolah Dasar. Kelola: Jurnal Manajemen Pendidikan, 4(1), 109.

https://doi.org/10.24246/j.jk.2 017.v4.i1.p109-120

Regulasi

Peraturan Menteri Pendidikan Nasional Nomor 70 Tahun 2009 tentang Pendidikan Inklusif Bagi Peserta Didik yang Memiliki Kelainan dan Memiliki Potensi Kecerdasan dan/atau Bakat Istimewa

Lain-lain

Pemkab Semarang Akan Siapkan Sekolah Khusus Bagi ABK, https://www.republika.co.id/be rita/nasional/daerah/19/04/23 /pqepid423-pemkab-semarangakan-siapkan-sekolah-khusussiswa-abk (diakses pada 5 Maret 2020)

Mewujudkan Sekolah Inklusi Merujuk Pada Pendidikan Untuk Semua, https://www.kompasiana.com/ twin/5a00470dc226f97a1a0f84 82/mewujudkan-sekolahinklusi-merujuk-padapendidikan-untuksemua?page $=$ all (diakses pada 5 Maret 2020) 